\title{
COVID-19, TRANSPORTE AÉREO E TURISMO EM MOÇAMBIQUE
}

\author{
COVID-19, AIR TRANSPORT AND TOURISM IN MOZAMBIQUE \\ COVID-19, TRANSPORTE AÉREO Y TURISMO EN MOZAMBIQUE
}

\begin{abstract}
RESUMO
O presente artigo tem como objectivo analisar o impacto do Covid-19 no sector de Turismo, com incidência para o papel dos transportes aéreos nesse processo. 0 espaço escolhido para a análise é Moçambique, um país em desenvolvimento, situado na África Austral de onde se elegeu um recorte espacial constituído pelos municípios de Maputo, Inhambane, Vilanculos e Pemba. Para o alcance do objectivo proposto, a opção foi por uma metodologia mista quali-quantitativa, multi-escalar, tendo-se recorrido, para a recolha de dados a revisão bibliográfica e documental e a entrevista, segundo um guião elaborado para o efeito. Os resultados do estudo revelam que o sector de turismo foi muito afectado pela pandemia, tanto de forma directa, com uma redução drástica do número de visitantes como consequência directa da pandemia, mas e sobretudo pela redução do número de voos por decisão, tanto dos países emissores como, mais tarde pelas autoridades de Moçambique. Ora, reduzindo, ao mínimo as possibilidades de movimentação internacional e nacional, os empreendimentos turísticos (alojamento e restaurantes) vêem desaparecer a sua principal fonte de renda. Assim, assistiu-se ao encerramento ou a redução de actividades de muitos empreendimentos com impactos, económicos e sociais negativos percebidos por todos os actores ou agentes do turismo.
\end{abstract}

Palavras-chave: Covid-19. Turismo. Transporte aéreo. Impacto. Moçambique.

\section{ABSTRACT}

This article aims to analyze the impact of Covid-19 on the Tourism sector, with evidence for the role of air transport in this process. The space chosen for observation is Mozambique, a developing country located in Southern Africa from which a spatial cut-out consisting of the municipalities of Maputo, Inhambane, Vilanculos and Pemba was chosen. To achieve the proposed objective, the option was for a mixed quali-quantitative methodology, multi-scalar, and the literature and documentary review and interview were used for data collection, according to a script prepared for this purpose. The results of the study show that the tourism sector has been greatly affected by the pandemic, both directly, with a drastic reduction in the number of visitors directly departing from the pandemic, but above all by reducing the number of flights by decision, both from issuing countries and later from Mozambique. However, by reducing, to a minimum the possibilities of international and national movement, the tourist enterprises (accommodation and restaurants) see their main source of income not appear. Thus, there has been the closure or reduction of activities of many undertakings with economic and social impacts perceived by all actors or agents of tourism.

Keywords: Covid-19. Tourism. Air transport. Impact. Mozambique.

\section{RESUMEN}

El presente artículo tiene por objetivo analizar el impacto del COVID-19 en el sector de turismo, y específicamente el rol del transporte aéreo en este proceso. El espacio de análisis elegido fue Mozambique, ubicado en África Austral, y se hizo un recorte espacial constituido por los municipios de Maputo, Inhambane, Vilanculos y Pemba. Para lograr el objetivo propuesto, optamos por una metodología cualicuantitativa mixta y multiescalar, utilizando, para la elección de datos, revisión bibliográfica/documental y entrevista. Los resultados del estudio revelan que el sector de turismo se vio muy afectado por la pandemia, tanto directamente (con una drástica reducción en el número de visitantes), como, sobre todo, por la reducción en el número de vuelos, por decisión de los países emisores y (más tarde) Mozambique. Con la reducción al mínimo de las posibilidades de movilidad

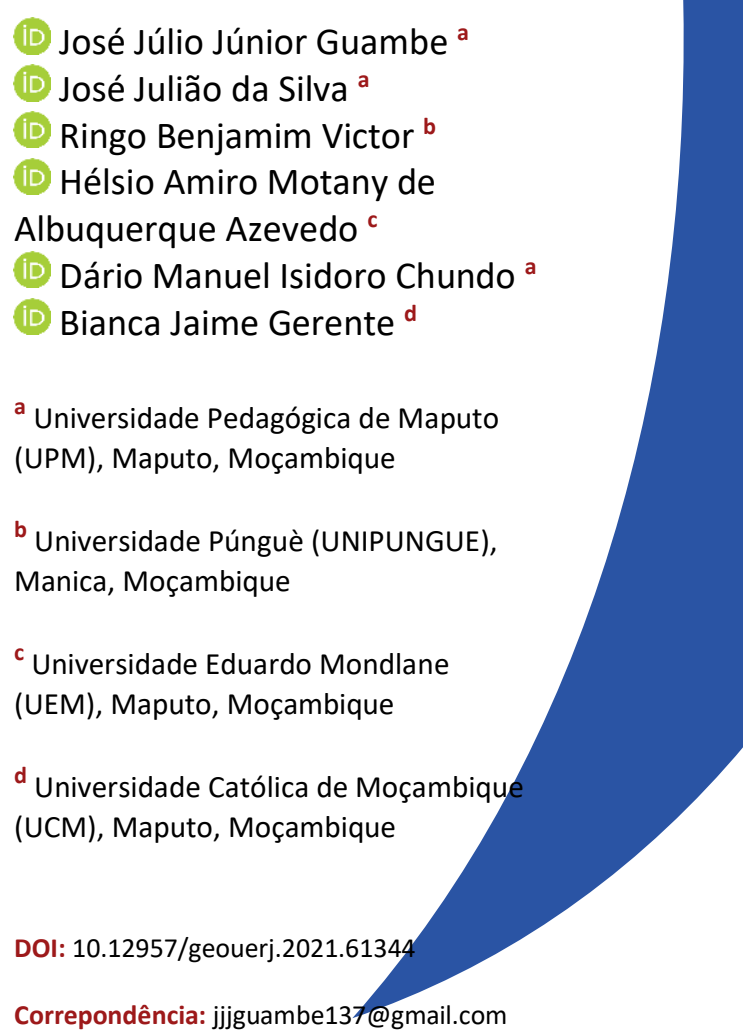

Recebido em: 8 mar. 2021

Aceito em: 18 jun.2021 
internacional y nacional, las empresas turísticas (alojamientos y restaurantes) presencian la desaparición de su principal fuente de ingresos. Así, muchos establecimientos han cerrado o reducido sus actividades, con impactos sociales y económicos negativos percibidos por todos los actores o agentes del turismo.

Palabras-clave: Covid-19. Turismo. Transporte aéreo. Impacto. Mozambique. 


\section{INTRODUÇÃO}

Moçambique é um país em desenvolvimento, localizado na África Austral que conta com um vasto leque de riquezas naturais, patrimoniais e culturais favoráveis ao desenvolvimento do turismo. Por essa razão, o Turismo é considerado um pilar para o desenvolvimento do país (MOÇAMBIQUE, 2004).

Nos países em vias de desenvolvimento em geral e em Moçambique, em particular, espera-se que o turismo tenha uma grande participação na luta contra a pobreza através da valorização dos recursos naturais e do património histórico-cultural que contribua de forma significativa para a promoção de investimento e de emprego, assim como, a geração de receitas em moeda externa.

Devido ao seu efeito multiplicador, o sector estimula outros sectores de actividades, exemplifica-se o sector de transporte, contribuindo dessa forma nos esforços da diversificação da economia.

Apesar dessa facilidade de integrar-se no desenvolvimento nacional/local, convém referir que o turismo é uma actividade vulnerável devido a sua dependência relativamente às condições ambientais e socioeconómicas. Para tal, e em relação à Moçambique, basta referir, por exemplo, as cheias do ano 2000 que afectaram a região sul, tendo tido implicações directas nos empreendimentos turísticos, mas igualmente nas infraestruturas de acesso aos destinos turísticos, de abastecimento de água, energia, entre outras. Actualmente, mais precisamente desde inícios do ano passado, a pandemia do novo coronavírus está tendo efeitos nefastos sobre o turismo no mundo em geral e em Moçambique, afectando, consequentemente os sectores correlatos, como o do transporte.

O turismo é uma actividade que envolve uma diversidade de actores, tanto nos locais de emissão como nos de recepção de turistas. Considerando o espaço de recepção, que é o foco neste estudo, evidenciam-se os seguintes actores: empreendedores do turismo (alojamento, restaurantes, agentes de viagens, transportadores, outros), as estruturas governamentais a diferentes níveis e a população desses espaços. Os actores locais, em geral, organizam-se, de forma articulada ou não, para receberem visitantes. Isto significa que, para que haja turismo devem existir condições que assegurem, no mínimo, os movimentos de chegada e de partida de visitantes, sendo que a ausência de visitantes não cria condições para o desenvolvimento do turismo.

Por outro lado, convém referir que, para que o turismo funcione de modo a que todos ganhem com o seu desenvolvimento, os actores ou agentes do turismo devem agir de modo articulado. Esta seria a situação ideal, o que, na prática, está muito longe de se verificar.

O presente artigo intitulado Covid-19, Transporte aéreo e Turismo em Moçambique procura analisar, de um modo geral, o impacto da pandemia da Covid-19 no turismo em Moçambique com uma incidência particular no sector dos transportes. Para a operacionalização deste objectivo geral, identifica-se e descrevem-se os efeitos directos e indirectos da pandemia no sector de turismo e faz-se o levantamento das medidas levadas a cabo para minimizar tais 
efeitos. No que concerne ao sector de transportes procura-se por em evidência a sua influência no desenvolvimento do turismo.

Esta pesquisa possui uma abordagem mista (quali-quantitativa). Para o alcance dos objectivos acima apresentados, para além de uma revisão bibliográfica e documental (MOÇAMBIQUE, 2004; AEROPORTOS DE MOÇAMBIQUE, 2021; MINISTÉRIO DA SAÚDE, 2021) e, tambem, foi realizada entrevista com o Presidente da Federação Moçambicana de Turismo e Hotelaria (FEMOTUR); a entrevista buscou a compreensão do estágio do sector de turismo e hotelaria em Moçambique diante da eclosão do Covid-19.

Para a elaboração do mapa recorreu-se a técnicas de geoprocessamento em ambiente SIG- Sistema de Informação Geográfica através do Software ARCGIS 10, versão ArcMap 10.3. Para o levantamento dos impactos da Covid-19 no sector de transportes, fez-se um recorte espacial de quatro municipios, designadamente, Maputo, Inhambane, Vilanculos ${ }^{1}$ e Pemba, com sua localização geográfica integrada na totalidade entre os paralelos $12 \circ 30^{\prime} 00^{\prime \prime}$ e 26 40'00" de Latitude Sul e, nos meridianos 320 00'00” e 39 30'00" de Longitude Este (Figura 1).

Figura 1. Mapa de localização geográfica da área de estudo. Fonte: Cenacarta, Moçambique

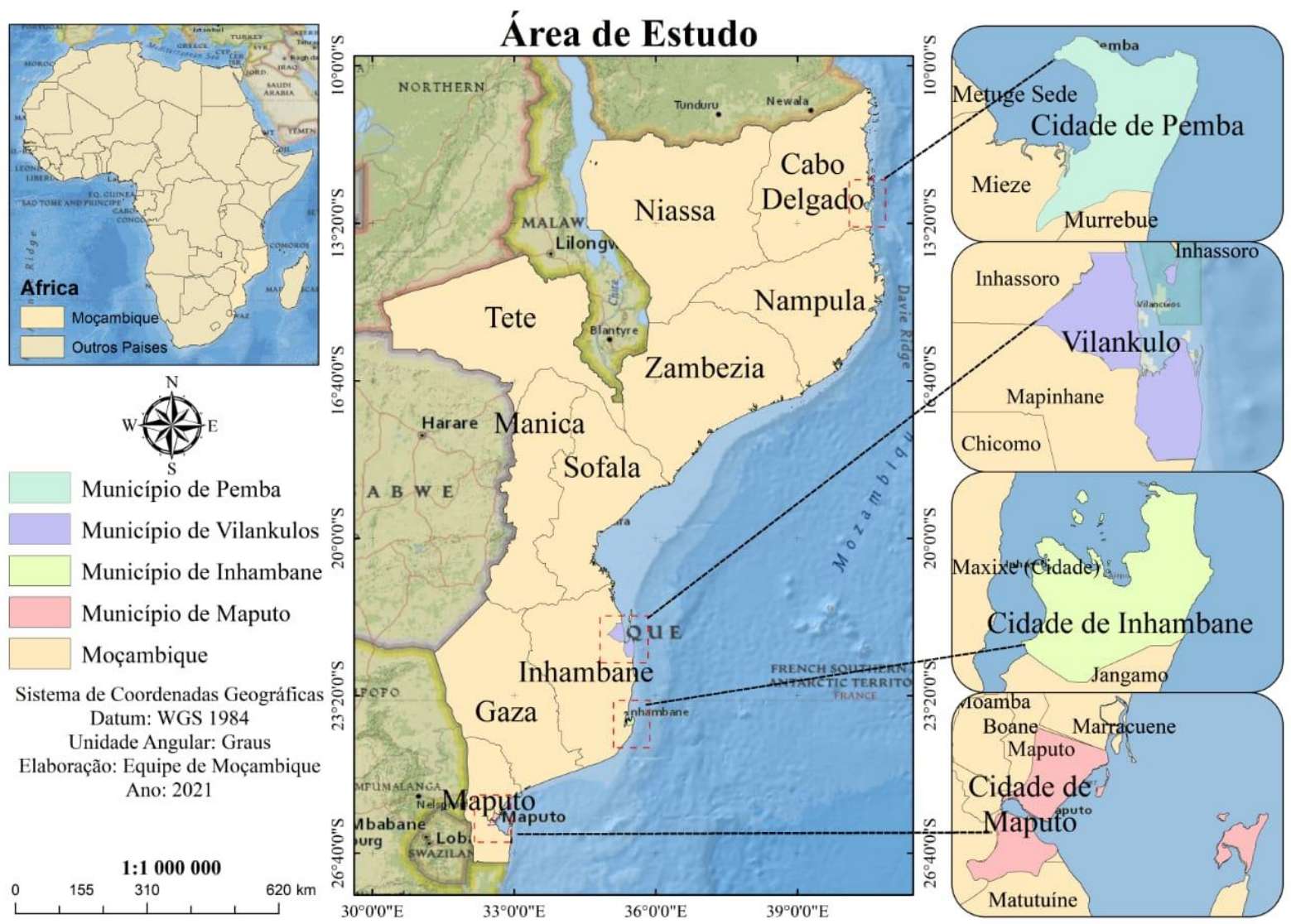

\footnotetext{
${ }^{1}$ Nome local que segundo Yassin, significa Vila Grande. No entanto a sua grafia ainda é muito variável podendo, também, encontrar-se escrito Vilanculo, Vilankulo ou Vilankulos. Disponível em

https://yassinamuji.com/amujiweb/mocambique/o-nome-e-vilankulo/ acesso em: 22/3/2021
} 
Estes locais foram escolhidos pela sua grande importância no panorama turístico do país, conforme os dados do Instituto Nacional de Estatísticas (2018). De acordo com dados dessa instituição, cerca de 35\% do parque hoteleiro localiza-se na cidade de Maputo, capital do país, onde se desenvolve basicamente um turismo urbano voltado para negócios e conferências, seguindo da província de Inhambane com 11\%, onde se concentra a prática do turismo de lazer (sol e praia) nos municípios de Inhambane e Vilanculos, e a província de Cabo Delgado, onde se localiza o município de Pemba, que participa com 5,4\%.

Vale ainda referir que, o tratamento de dados contemplou três etapas: fase de pré-análise, exploração do material e tratamento dos resultados obtidos e sua interpretação.

Para o estudo foi usada, igualmente, uma base de dados secundária disponibilizada pela Empresa Aeroportos de Moçambique, onde foram levantadas as seguintes variáveis: número de voos nacionais e internacionais e; número de passageiros nacionais e internacionais em um período bienal (2019 a 2020), referente a 24 meses dos municípios de Maputo, Inhambane, Vilanculos e Pemba.

Para além da introdução, onde foram apresentados os objectivos e a metodologia, o trabalho comporta ainda uma breve caracterização dos actores do turismo e do seu modo de articulação; impactos da Covid-19 em Moçambique que se divide em duas partes: impactos gerais da Covid-19 sobre o turismo e Moçambique e Covid-19, Transportes aéreos e Turismo. No final apresentam-se as considerações finais.

Breve caracterização dos actores do turismo e sua articulação em Moçambique

No processo de desenvolvimento da actividade turística estão envolvidos diversos actores ou agentes. Knafou (1999, p.70) designa-os de "agentes da turistificação" e destaca a participação no processo, três agentes, nomeadamente os turistas, o mercado e os planificadores e promotores territoriais, ou seja, o Estado.

Do mesmo modo, Cruz (2003) refere que, os turistas, como "visitantes pioneiros" dos lugares, são os agentes que estão na base da transformação de determinado local em lugar turístico, pois,

[...] diversos lugares foram e ainda são inventados como lugares turísticos em função da prática espontânea de certos turistas, ou seja, sem a mediação do mercado. Neste caso, são esses visitantes pioneiros, que estão na base da transformação de determinado local em lugar turístico (CRUZ, 2003, p.14).

A autora acrescenta que, o mercado, representado pelo capital privado, pelos empreendedores do sector turístico, é hoje o principal responsável pela produção dos lugares de uso turístico e, por fim, os planificadores e promotores territoriais como os agentes de produção dos lugares de uso turístico que têm uma ligação mais próxima com o lugar. "Trata-se, nesses casos, de iniciativas locais, regionais ou mesmo nacionais, assumidas pelos respectivos poderes políticos" (CRUZ, 2003, p.15). 
Na mesma linha, Fratucci (2015) concorda que no processo de produção do espaço de uso turístico, estão envolvidos diversos agentes, onde se destaca mais um para além dos três identificados por Knafou (1999) e Cruz (2003), que é a população residente nos lugares de uso turístico, assim como, os trabalhadores directa ou indirectamente envolvidos com o turismo.

No nosso entender e no caso de Moçambique, todos os quatro agentes actuam como sujeitos do fenómeno turístico de maneira específica, segundo as suas lógicas, e é da articulação dessas lógicas que se constrói o espaço de uso turístico moçambicano e se pode entender os impactos da pandemia da Covid-19 no turismo. Conforme Fratucci (2015), partindo do entendimento do turismo como fenómeno sócioespacial complexo e dinâmico, resultado da aç̧ão de diversos grupos de agentes sociais em determinadas porções do espaço, é essencial a compreensão das lógicas territoriais que cada um desses agentes adopta para a satisfação das suas demandas e expectativas.

Neste contexto, o mercado, como principal agente do turismo é um dos promotores de desenvolvimento do turismo, guiado pela lógica do capital e do lucro, como refere Fratucci (2015), este articula as suas acções com os outros três agentes de diferentes maneiras.

De acordo com Guambe (2018), no caso de Moçambique, a articulação com as populações locais acontece basicamente no início do estabelecimento dos empreendimentos e esporadicamente durante o exercício das suas actividades, por via da exploração permanente e sazonal de pouca mão de obra, pois, pela via produtiva, as populações locais, ainda não são capazes de responder às necessidades colocadas pelo exigente mercado turístico. Esta articulação inicial acontece durante as negociações, visando a apropriação da terra, para a instalação de uma "tecnoesfera" de uso turístico.

Por outro lado, ao longo do processo de desenvolvimento turístico, os agentes do capital, articulam com o Estado, e vice-versa, através das suas distintas instâncias de governo, em diversas escalas. Todavia, tal como referem Santos (2000), Cruz (2003) e Fratucci (2015), na actualidade a força dos agentes do capital tem cooptado as diversas instâncias do governo, levando-as a actuarem sob uma lógica mais reticular, privilegiando as suas acções.

Nesse contexto, como salienta Fratucci (2015), a contradição no papel exercido pelo Estado é evidente, isto é, o duelo entre o interesse público e o interesse privado é constante; e, segundo Santos (2000) e Cruz (2003), na articulação entre estes dois agentes do turismo, há claramente, subserviência do Estado em relação aos interesses e as demandas do mercado.

Finalmente, a articulação dos agentes do capital com os turistas. Esta é feita a partir da informação ao serviço do consumo, isto é, dos diversos meios de comunicação existentes, com maior domínio para as chamadas tecnologias de informação e comunicação e de publicações especificas editadas pelos agentes do 
capital, procurando, segundo Rodrigues (1997), explorar as aspirações mais profundas do indivíduo que viaja fazendo apologia da natureza e do sexo. Alguns resumem esses aspectos na fórmula $4 \mathrm{~S}$ (sea, san, sun e sex ou seja, na tradução literal, mar, areia, sol e sexo).

Resumindo, a articulação entre os agentes do mercado e os turistas, e vice-versa, é feita, sobretudo, nos pólos emissores, onde são colocados os lugares de uso turístico, de acordo com Carlos (1996), no "circuito da troca" ou, segundo Cruz (2007), no "circuito das mercadorias", e nos pólos receptores, através da oferta dos diversos produtos turísticos.

De acordo com Guambe (2018), em Moçambique, os turistas, maioritariamente sul-africanos, agindo segundo uma lógica bastante específica, destinada a atender às suas necessidades e demandas no tempo de lazer, articulam directa e reticularmente com os agentes do mercado turístico, também, maioritariamente sulafricanos, que exploram quase toda a cadeia de serviços turísticos no país.

O mesmo autor, refere, ainda, que esta cadeia comporta desde o agenciamento do transporte e do alojamento, no local de origem, ao comércio de bens em supermercados e lojas de conveniência, restaurantes e serviços especializados, como por exemplo, aluguer de barcos e instrumentos de pesca e ou de mergulho, aulas de mergulho, etc..

A articulação entre os turistas e a população local, bem como com o Estado é muito incipiente, limitando-se à compra de alguns produtos nos mercados formal e informal, basicamente souvenirs, principalmente nas praias. Possuem também, apenas uma articulação formal com o Estado, enquanto autoridade que gere a imigração, ou com a polícia de trânsito, durante o percurso de ida e volta para lugares de uso turístico.

Em suma, depois desta análise sobre a articulação entre os quatro agentes do turismo, que muitas vezes, culmina com a segregação económica e sócioespacial, verticalmente imposta pela lógica do capital, aliada à sua fraca relação com a lógica da vida quotidiana das populações locais e dos trabalhadores directa ou indirectamente envolvidos com o turismo, como um dos agentes do turismo, é possível constatar, diante do flagelo imposto pela pandemia da Covid-19 o quão frágeis é esta articulação e quão vulneráveis são os agentes e os lugares receptores do turismo, bastando para tal, analisar as crises e os impactos desta pandemia em Moçambique.

Impactos da pandemia Covid19 em Moçambique

Não existe, ainda, alguma certeza sobre a real origem do novo vírus da família coronavírus, designado Sars-CoV-2, responsável pela doença respiratória denominada Covid-19. A única certeza, amplamente 
divulgada na mídia internacional, é que os primeiros casos da manifestação da doença verificaram-se na cidade de Wuhan, na província chinesa de Hubei nos finais de 2019.

O aparecimento do novo coronavírus foi identificado após o surgimento de casos de pneumonia, com causas desconhecidas, em Wuhan. Contudo, a Covid-19 pode causar diversos tipos de infeções respiratórias cujos sintomas assemelham-se aos de resfriados e gripes, como espirros, tosse, coriza e febre, podendo, no entanto, elevar-se para situações mais graves como pneumonia, insuficiência respiratória aguda, lesões pulmonares e até a morte.

A sua transmissão pode ocorrer através do contato com pessoas e ou animais contaminados e ou toque de superfícies contaminadas onde o vírus pode sobreviver por várias horas ou dias. A transmissão da Covid-19 entre pessoas pode ocorrer através de gotículas de secreções eliminadas pelos doentes sintomáticos ou assintomáticos, durante a tosse, espirro ou a partir de objectos contaminados e os canais de penetração da doença são a boca, as narinas e os olhos.

Desta maneira, a disseminação geográfica da Covid-19 foi, e está sendo, muito fácil e rápida, devido a grande mobilidade espacial humana e a conectividade da sociedade actual, garantida pelo moderno e superrápido equipamento de transporte que flui numa rede fortemente conectada. De acordo com a Organização Mundial da Saúde (OMS), citada por Guambe (2019), desde 31 de Dezembro, quando a China informou a OMS que um vírus, até então desconhecido, estava se espalhando pelo país, até 11 de Março de 2020, a Covid-19 já tinha chegado a 114 países, infectado mais de 118 mil pessoas e morto outras 4.291. Actualmente, a pandemia já registou $117,132,788$ casos confirmados e 2,600,839 mortes, em todo o planeta (OMS, 2021). Desde a sua eclosão, segundo dados apresentados na Worldometer (2021) morreram aproximadamente 2.700.000 de habitantes em todo o planeta, situação que levou autoridades governamentais a tomarem medidas restritivas de deslocação de pessoas pela facilidade de contaminação deste vírus.

Foi neste contexto de grande escalada e velocidade do Sars-cov-2, que há um ano (11 de Março de 2020), a OMS classificou a Covid-19, como pandemia, e daí em diante o número de novos casos positivos, mortes e lugares atingidos foi crescendo exponencialmente em todo planeta, e novas variantes (cepas), mais contagiantes e mortíferas, vão surgindo, como é o caso da chamada variante Sul-africana.

Em Moçambique, o primeiro caso positivo foi diagnosticado no dia 22 de Março, no município de Maputo, um dos recortes espaciais da presente pesquisa, importado de Londres. Todavia, de acordo com os dados do Ministério da Saúde (MISAU, 2021), em pouco tempo, cerca de ano depois, o país conta com 62,882 casos positivos cumulativos e 700 mortes, distribuídos por todo o país (Figura 2). 
Figura 2. Distribuição de casos confirmados de Covid-19 por província. Fonte: MISAU. Boletim Diário № 357, actualizado em $9 / 3 / 2021$

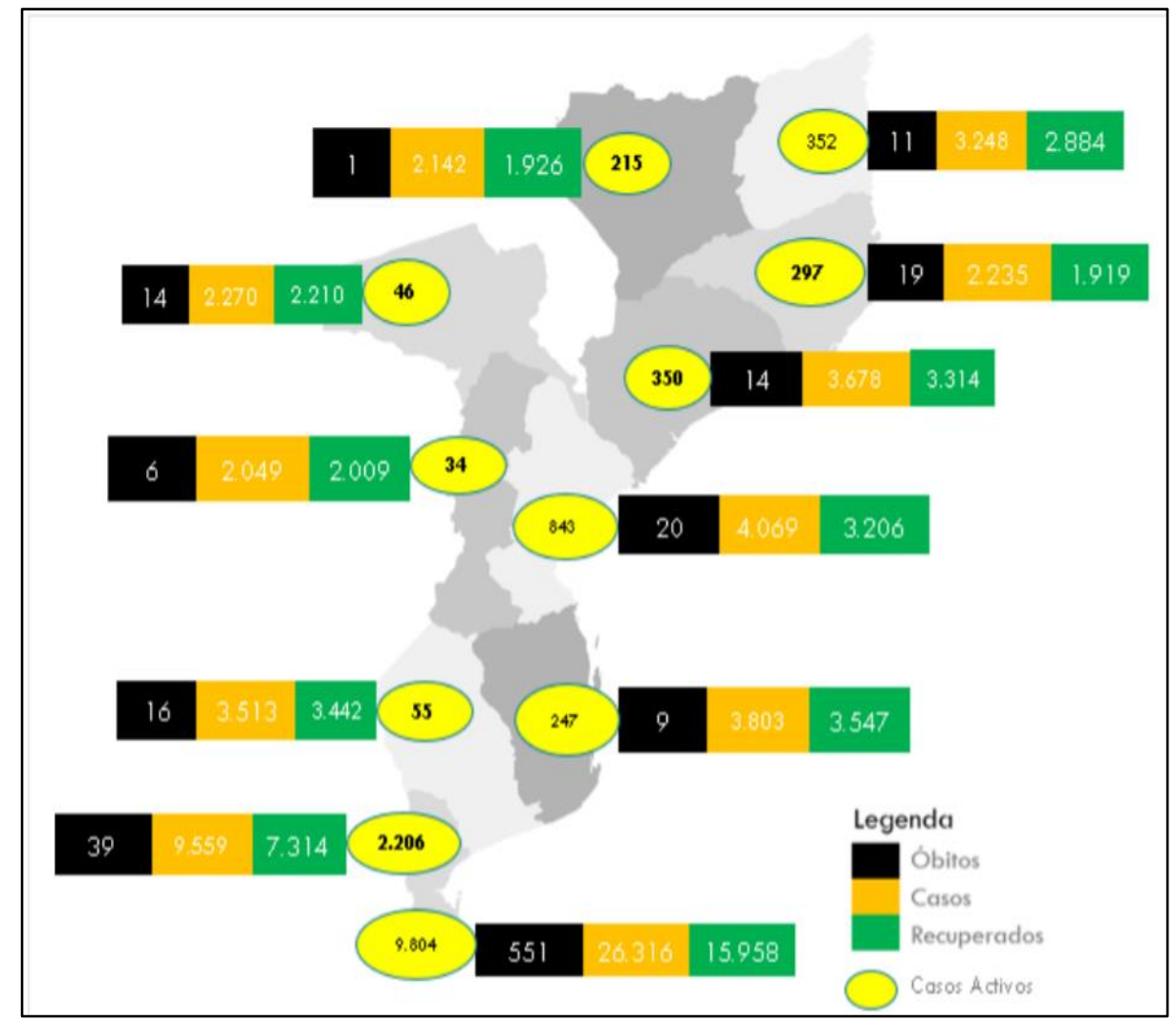

Com base nos dados apresentados na figura 2, constata-se que os quatro municípios objectos de análise, apresentam cumulativamente mais da metade dos casos do país (52.9\%), onde se destaca o município de Maputo, com $41.8 \%$ dos casos positivos da doença e $78.7 \%$ das mortes por Covid-19. A província de Inhambane, onde se localizam os município de Inhambane e Vilanculos, apresenta $6.0 \%$ dos casos e $1.2 \%$ dos óbitos, enquanto que a província de Cabo Delgado, onde localiza o município de Pemba, apresenta $5.1 \%$ e $1.5 \%$ de casos e óbitos, respectivamente.

Por conseguinte, os seus efeitos sociais e nas economias global e regional estão relacionados à sua rápida disseminação geográfica, isto é, a sua pandemização, motivada pelos processos da sua transmissão que consistem principalmente no contato interpessoal entre infectados e não infectados, e o curto tempo de incubação, que varia entre 5 a 14 dias, conforme a OMS.

Em Moçambique, a pandemia do coronavírus está a provocar vários e graves impactos negativos, que vão crescendo diariamente, principalmente nas duas esferas (económica e social), com destaque para sérios problemas de saúde pública causados pelas dificuldades do governo fazer face à doença que, até ao momento, não tem cura e o processo de vacinação acaba de iniciar, com garantias relativas. Neste contexto, a prevenção da Covid-19 está sendo feita privilegiando-se o isolamento social e medidas de higiene, como lavagem das mãos e o uso de máscaras (MOÇAMBIQUE, 2020a). 
Por isso, de acordo com Guambe (2019), a prática do isolamento social ou confinamento, como uma das principais formas de prevenção, cristalizado nos apelos e/ou determinações como "Fica em casa", escalonados em diversos níveis, desde o simples distanciamento social até ao recolher obrigatório, um dos seus extremos radicais, desencadeou, por sua vez, uma outra série de consequências, onde se destaca a paralisação total ou parcial de várias actividades socioeconómicas, principalmente as que se relacionam com a mobilidade e o contato interpessoal, onde se destaca o turismo e o transporte, em particular, o aéreo.

Impactos do Covid-19 sobre o Turismo em Moçambique: dados preliminares

No que tange ao turismo, considerando que uma das características fundamentais da prática socioespacial do turismo é a mobilidade e o contato interpessoal, é evidente que o temor de Moçambique em correr riscos de ver a sua população infectada pela Covid-19, atendendo a gravidade da sintomatologia e a inexistência de estruturas de saúde à altura, levou o país a tomar como uma das primeiras medidas, a restrição e controlo da mobilidade interna e o cancelamento da externa, através do fecho da emissão de vistos e das fronteiras (MOÇAMBIQUE, 2020a).

Deste modo, em Moçambique, onde basicamente predomina, neste momento, o turismo de negócios, principalmente no município Maputo, e o de lazer no resto do país, particularmente nos municípios de Inhambane, Vilanculos e Pemba, devido as medidas decretadas no âmbito dos Estados de emergência e de calamidade pública (MOÇAMBIQUE, 2020a, 2020b), com vista a contenção da propagação da pandemia do coronavírus, como por exemplo, a limitação de entradas e saídas no e do território nacional, as restrições de mobilidade interna, a proibição de reuniões e/ ou encontros com mais de vinte pessoas, os recorrentes apelos ao isolamento social, o encerramento de praias, o encerramento de serviços de entretenimento, o recolher obrigatório na zona metropolitana do grande Maputo, entre outras, boa parte ligadas ao lazer, têm trazido vários impactos económicos e sociais.

De acordo com Guambe (2019), a partir do momento que as informações sobre a existência e avanço do Coronavírus, começaram a disseminar-se pelo planeta, o sector do turismo em Moçambique, sofreu perdas no volume de reservas nos meses Janeiro, Fevereiro e Março de 2020, em 35\%, 45\% e 65\%, respectivamente. Estas perdas perfazem uma média trimestral de $48 \%$ em comparação com o mesmo período de 2019 , embora, até ao último dia de Março de 2020, Moçambique, ainda não tivesse nenhuma restrição de mobilidade seja interna ou externa, situação que alterou no primeiro dia de Abril de 2020, com o início da vigência do primeiro Estado de emergência (MOÇAMBIQUE, 2020a), motivado neste caso, pela pandemia do Covid-19.

De maneira idêntica, a Confederação das Associações Económicas de Moçambique (CTA) considerando que esta situação de perdas se observe num cenário otimista, previa que o desempenho do sector do turismo poderia sofrer prejuízos em cerca de $80 \%$ no primeiro semestre, o que se traduziria numa perda de aproximadamente $3.4 \mathrm{Mil}$ 
Milhões de Meticais (MZN), enquanto que, num cenário pessimista, este sector poderia perder em cerca de 95\%, traduzindo-se num prejuízo de negócio no sector, estimado em 4,6 Mil Milhões de Meticais.

Além disso, ainda em relação aos impactos da pandemia sobre o turismo em Moçambique, segundo informação oficial do Ministério de Cultura e Turismo de Moçambique (MICULTUR, 2020), dos 2462 estabelecimentos hoteleiros, 3986 bares e restaurantes e 336 Agências de Viagens existentes no país, um total 696 já encerraram, sendo 155 estabelecimentos hoteleiros, 484 bar e restaurantes, 12 agências de viagens e 45 salas de dança, incluindo todos os casinos e as salas de máquinas de jogos de fortuna ou azar. De acordo com a mesma fonte, estes encerramentos puseram em causa 3511 postos de trabalho.

Segundo declarações de Cunha (2021), Presidente da Federação Moçambicana de Turismo e Hotelaria (FEMOTUR), o sector do Turismo em Moçambique registou baixo crescimento depois da eclosão da pandemia Covid19, visto que, cerca de 42 mil trabalhadores foram suspensos, houve um défice de tesouraria de $90 \%$, correspondente a 385 milhões de Meticais e registou-se perda de facturação de aproximadamente 428 milhões de Meticais. O Cta \& Femotur (2020, p. 7) salientam este cenário ao abordarem que:

\begin{abstract}
O sector da Hotelaria e Turismo emprega aproximadamente 64 mil trabalhadores, distribuídos em estabelecimentos de alojamento, restaurantes e agências de viagem. Devido a Covid-19 cerca de 65\% dos postos de trabalho foram suspensos e estão em risco. Agregando o impacto da Covid-19 sob ponto de vista de perda de receitas e sob ponto de vista de défice de tesouraria, estima-se que esta pandemia teve um custo financeiro de aproximadamente 1500 Milhões de Meticais só no primeiro semestre do ano.
\end{abstract}

As notícias sobre o encerramento de estabelecimentos turísticos e perdas de emprego em Moçambique, particularmente em Inhambane, principal província turística do país, são constantes, quase que diárias. De acordo com Hugo Firmino², repórter de uma televisão privada nacional, numa reportagem de 3 de Maio de 2020, desde Fevereiro daquele ano, o cenário que se vive em toda província de Inhambane é considerado terrível. Não há ninguém na recepção das estâncias turísticas, mas também não há ninguém para receber. As autoridades de turismo previam receber pouco mais de 16 mil turistas nas férias da Páscoa de 2020, mas a pandemia da Covid-19 veio deitar abaixo todas as expectativas e logo que a doença começou a alastrar-se, os cancelamentos de reservas começaram a chegar. De acordo com a mesma fonte, cerca de 130 estâncias turísticas fecharam as portas em Inhambane, deixando em casa pouco mais de 1400 trabalhadores.

Em suma, os impactos sociais e económicos da pandemia da Covid 19 sobre o turismo, em 2020, foram muito negativos e continuam sendo nos dias que correm, pois, a doença continua activa e com efeitos cada vez maiores sobre a saúde pública, que obrigam a manutenção e o incremento das medidas de prevenção, em particular, o distanciamento social e o uso de máscaras.

\footnotetext{
${ }^{2}$ Disponível em: http://opais.sapo.mz/mais-de-130-estancias-turisticas-fecham-as-portas-em-inhambane - acesso em: 4/5/2020.
} 
Covid-19 e seus impactos no sector de transporte aéreos em Moçambique

O sector de transportes, em particular o aéreo, analisado por diversos autores, entre eles O'keefe (2020), Monié (2020) e Guambe (2019), é considerado um dos grandes vetores da mundialização da Sars-CoV-2. Este sector viu a sua actividade drasticamente reduzida, durante o ano de 2020, como resultado das medidas tomadas, interna e externamente, para a contenção da propagação e disseminação do Covid-19.

Ao analisar-se a situação do transporte aéreo nos municípios de Maputo, Inhambane, Vilanculo e Pemba, a partir da comparação de quatro indicadores, nomeadamente, a evolução mensal do número de voos nacionais e internacionais, e a evolução mensal do número de passageiros nacionais e internacionais, tomando como base os anos de 2019 e 2020, são claramente visíveis os impactos negativos sobre o sector dos transportes aéreos em Moçambique.

Com efeito, segundo os dados mensais de evolução do número de voos nacionais, em 2019 e 2020, nos quatro municípios, verifica-se, por um lado, uma grande redução anual do número de voos nas seguintes proporções: Maputo, 39.3\%; Inhambane, 67.2\%; Vilanculo, 70.6\%; e Pemba, 7.6\% e, por outro, uma diminuição mensal de janeiro a setembro em todos os municípios, seguida de uma ligeira subida, nos três últimos meses de 2020, conforme ilustrado nos gráficos apresentados na figura 3.

Figura 3. Evolução mensal do número de voos nacionais - 2019 e 2020. Fonte: Aeroportos de Moçambique, E.P. - 2021
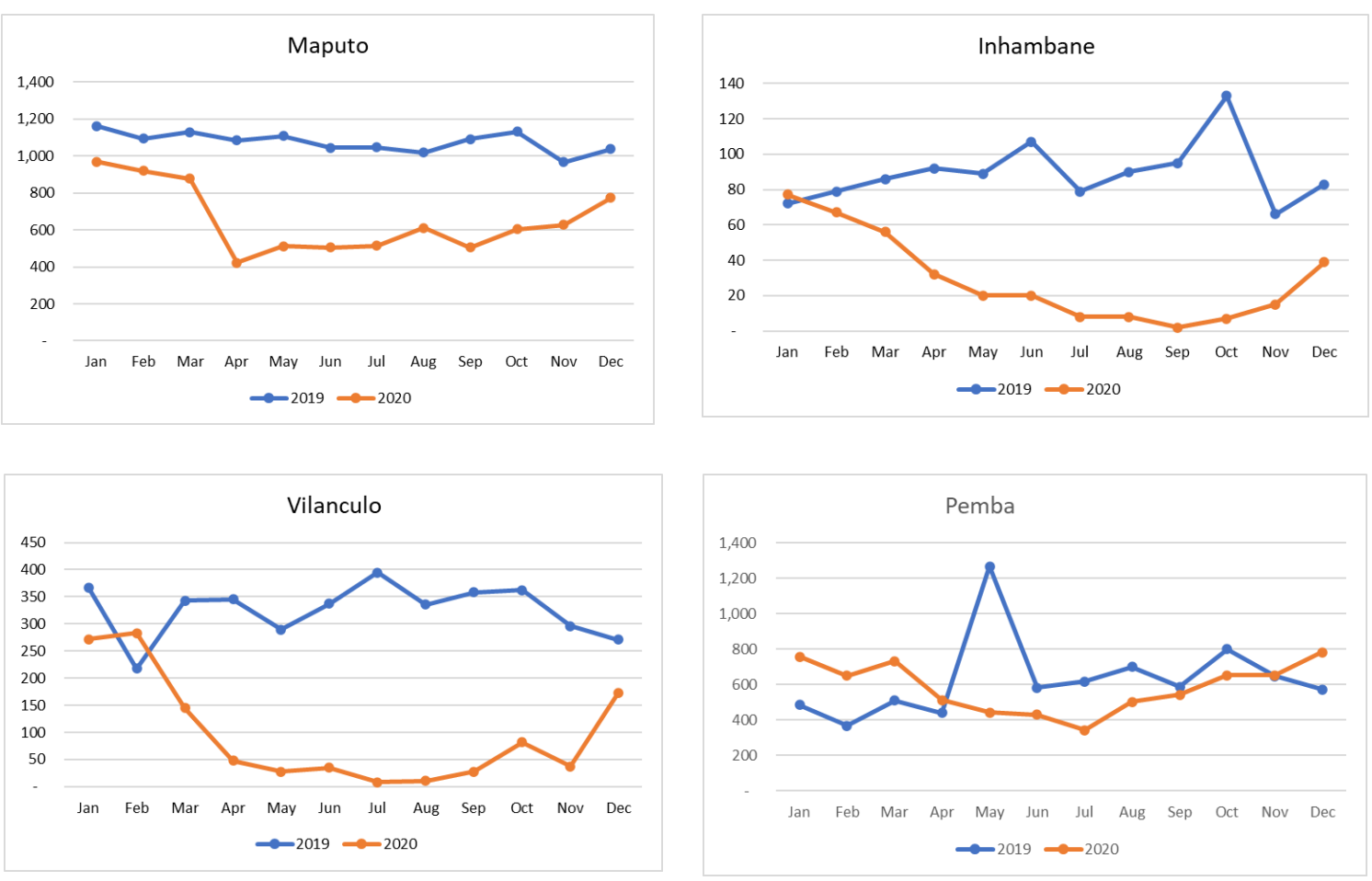
Por conseguinte, esta redução do número de voos nacionais nos primeiros noves meses de 2020, principalmente a partir de abril, está relacionada com a implementação das medidas de restrição de mobilidade emanadas no Decreto n.일 12/2020 referentes ao Estado de emergência determinado pelo governo, no inicio do mês de abril de 2020, e a subida no último trimestre, eventualmente, ao relaxamento das mesmas através do Decreto n.ำ9/2020 (MOÇAMBIQUE, 2020b).

Todavia, importa esclarecer o baixo impacto sobre o número de voos nacionais no município de Pemba (7.6\%), comparativamente ao resto do país. Com efeito, ainda que as medidas restritivas tivessem uma cobertura nacional, o município de Pemba, capital da província nortenha de Cabo Delgado, continuou a receber voos nacionais regularmente, devido a trágica situação militar e humanitária que a região vive, relacionada ao terrorismo, daí a grande mobilidade militar e de solidariedade, mas também, devido a grande mobilidade ligada aos projetos de prospeção e extração de gás natural no distrito de Palma, e sanitária, pois, no segundo e terceiro trimestres de 2020 , os acampamentos do projecto de gás, em Afungi, se tornaram no primeiro epicentro de propagação do coronavírus em Moçambique (GUAMBE, 2019).

Similarmente, na análise da situação dos voos internacionais em Moçambique, também, são nitidamente visíveis os impactos negativos da pandemia, sobre o sector dos transportes aéreos. Do mesmo modo, os dados mensais de evolução do número de voos internacionais, em 2019 e 2020, nos quatro municípios, mostram, por um lado, uma grande redução anual do número de voos nas seguintes proporções: Maputo, 60.3\%; Inhambane, 77.7\%; Vilanculos, 75.6\%; e Pemba, $63.5 \%$ e, por outro, uma queda abruta nos primeiros três meses de 2020, um período difícil, de abril à setembro, sem voo nenhum em alguns meses, nos municípios de Inhambane e Vilanculos e, seguida de uma ligeiras subida, no último trimestre do ano, conforme ilustrado nos gráficos apresentados na figura 4.

Figura 4. Evolução mensal do número de voos internacionais - 2019 e 2020. Fonte: Aeroportos de Moçambique, E.P. - 2021
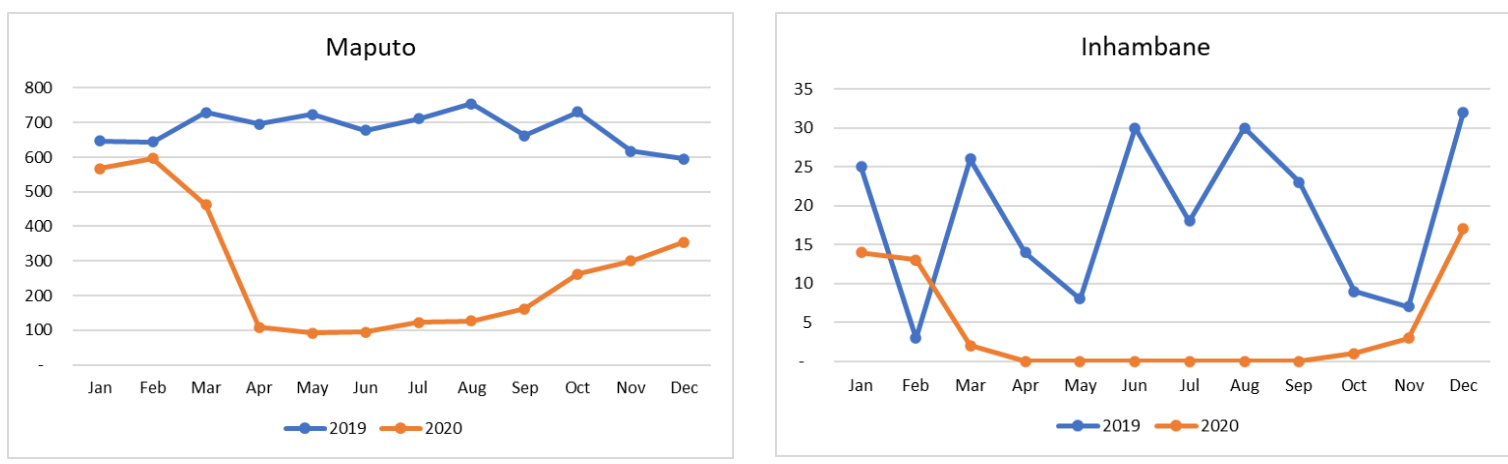

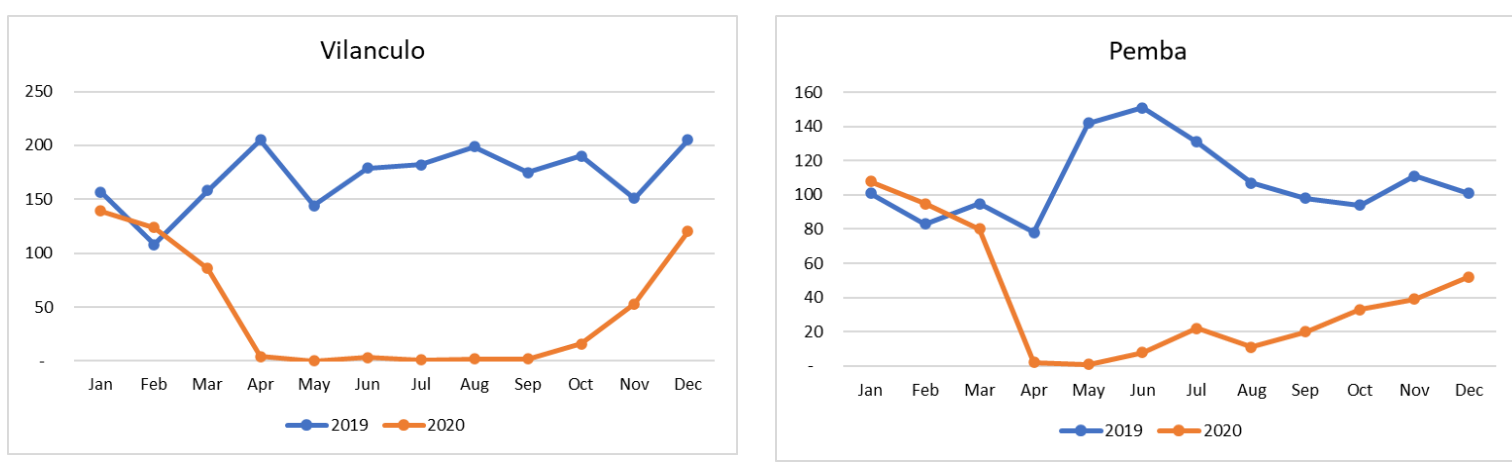

Da mesma forma, o período difícil para a aviação internacional em Moçambique e a ligeira subida do número de voos nos últimos três meses de 2020, está relacionada com a implementação das medidas de restrição de mobilidade emanadas nos decretos referentes ao Estado de emergência determinado pelo governo, no inicio do mês de abril de 2020, e eventualmente, ao seu relaxamento no último trimestre.

Entretanto, a queda brusca do número de voos internacionais no primeiro trimestre de 2020 , em Moçambique, não pode ser explicado pela implementação das medidas restritivas internas, pois, até então, o país ainda não tinha adotado nenhuma medida, mas sim pelas medidas externas, uma vez que, várias companhias aéreas internacionais, estavam restringindo os seus voos, por suspeição de serem os causadores da disseminação do Sars-CoV-2, impactando inicialmente, desse modo, sobre o turismo internacional, no país.

Como resultado, ainda que não exista necessariamente uma relação causa e efeito, entre os voos e os passageiros, no entanto, sendo o turismo, entre outros elementos, mobilidade, o número de passageiros/viajantes impacta sim neste fenómeno socioespacial.

De fato, na análise da situação de passageiros, são, também, muito visíveis os impactos negativos da pandemia do Covid-19, sobre o sector dos transportes aéreos. De igual modo, os dados mensais de evolução do número de passageiros nacionais, em 2019 e 2020, nos quatro municípios, mostram, por um lado, uma grande redução anual nas seguintes proporções: Maputo, 43.3\%; Inhambane, 68\%; Vilanculos, 66.1\%; e Pemba, $14.2 \%$ e, por outro, uma queda vertiginosa nos primeiros três meses de 2020, seguido de estabilidade baixa a muito baixa, em Inhambane e Vilanculos, entre abril e setembro, e, uma ligeiras subida, no último trimestre do ano, enquanto que nos municípios de Maputo e Pemba a situação foi caracterizada por um progressivo crescimento a partir dos meses de abril e maio, conforme ilustrado nos gráficos apresentados na figura 5. 
Figura 5. Evolução mensal do número de passageiros nacionais - 2019 e 2020. Fonte: Aeroportos de Moçambique, E.P. - 2021
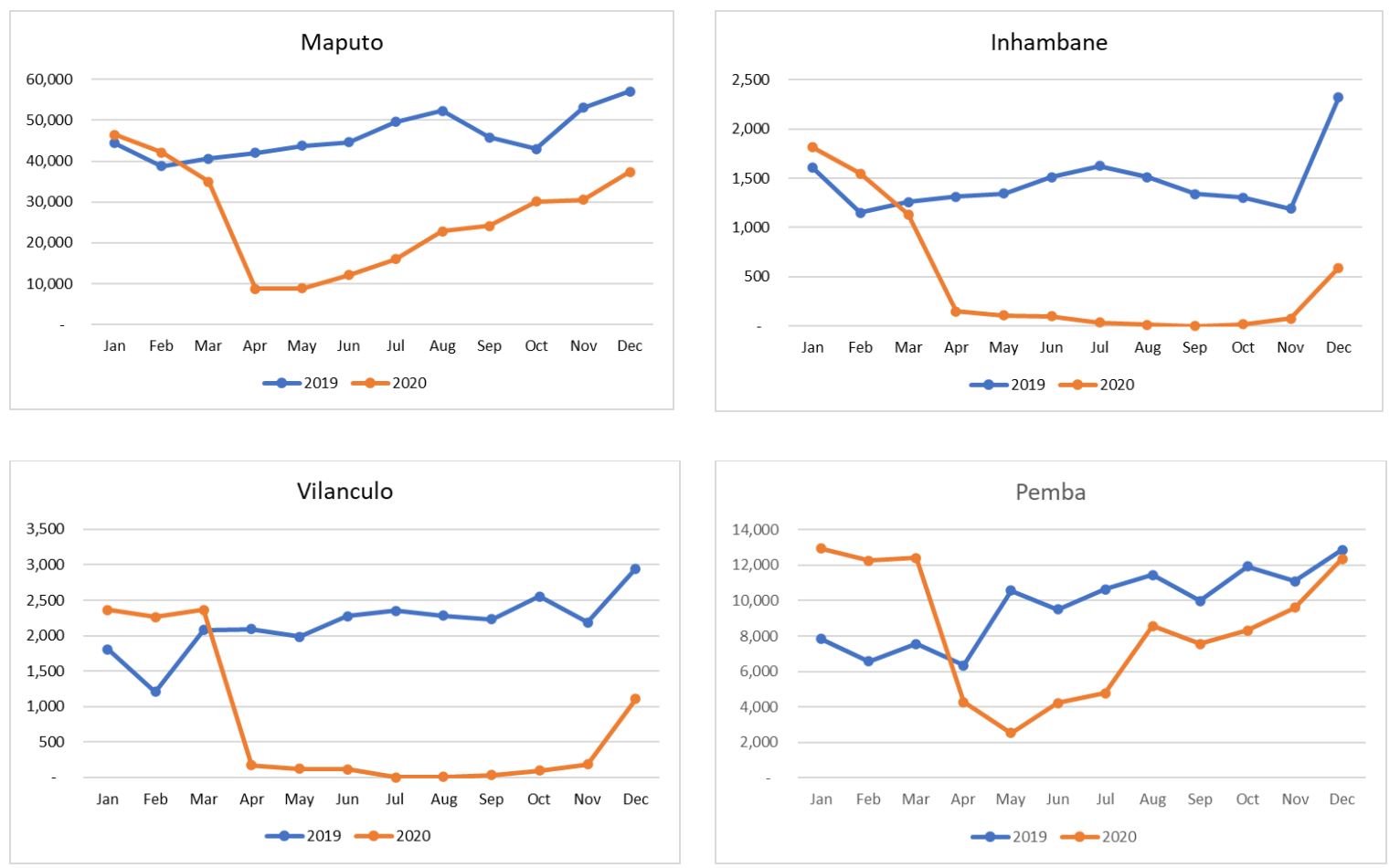

$\mathrm{Na}$ análise da situação dos passageiros internacionais em Moçambique, conforme se apresenta na figura 6, são visíveis os impactos negativos do Covid-19, sobre o sector dos transportes aéreos e, por conseguinte, sobre o turismo internacional. Similarmente, os dados mensais de evolução do número de passageiros internacionais, em 2019 e 2020, nos quatro municípios, mostram, por um lado, uma grande redução anual do número de passageiros nos municípios de Maputo, 71.9\%; Inhambane, 73.4\%; Vilanculos, 75.5\%; e Pemba, $56.1 \%$ e, por outro, uma queda acentuada nos primeiros três meses de 2020 , seguido de um período totalmente negativo, de abril à outubro, principalmente, nos municípios de Inhambane e Vilanculos e, seguida de uma ligeiras subida, no último dois meses do ano, conforme ilustrado nos gráficos apresentados na figura 6. Importa aclarar que os aeroportos dos municípios de Inhambane e Vilanculo estiveram encerrados por seis meses, razão da drástica redução de passageiros e voos observada nas figuras 4 e 5.

Figura 6. Evolução mensal do número de passageiros internacionais - 2019 e 2020. Fonte: Aeroportos de Moçambique, E.P. - 2021
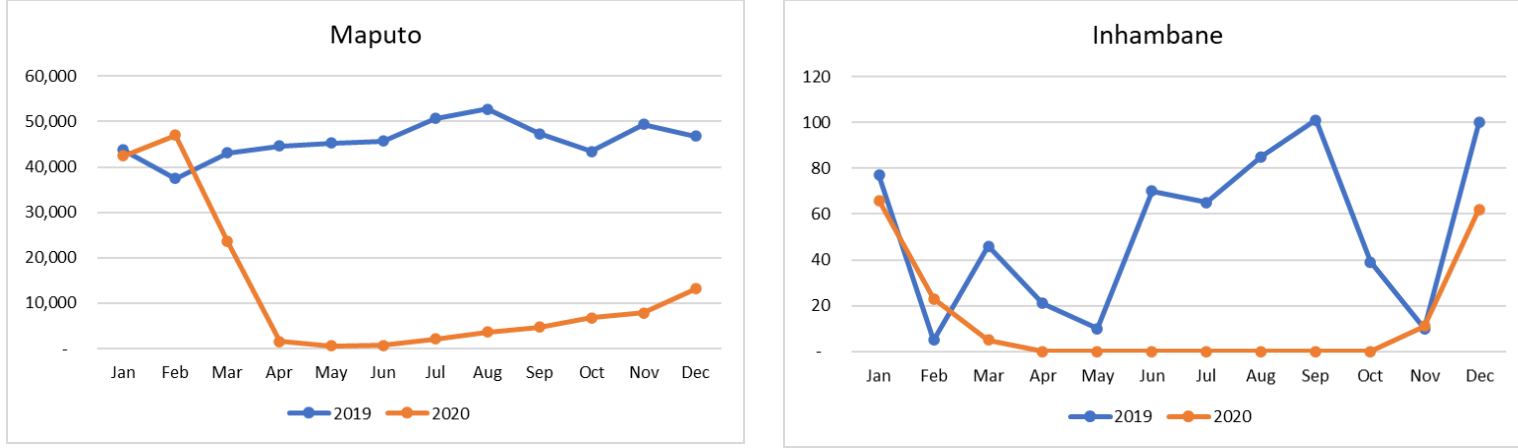

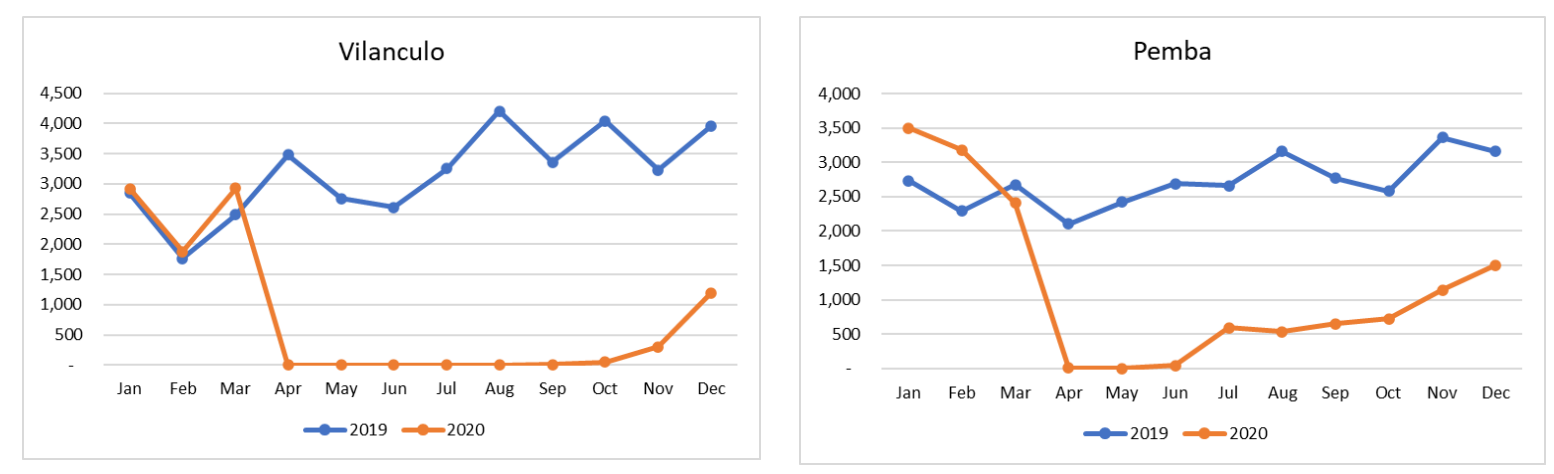

Da mesma forma, estas reduções do número mensal de passageiros nos voos internacionais, tanto nos primeiros três meses de 2020, como nos subsequentes, estão directamente relacionadas, em primeiro lugar, com a conjuntura externa, e em segundo lugar, com a implementação das medidas restritivas de mobilidade emanadas nos decretos referentes ao Estado de emergência, que incluíam a supressão de vistos, enceramento dos locais de lazer, entre outros, impactado deste modo na actividade turística.

Conforme apresentado pelo Jornal Notícias (2020), as perdas registadas no sector dos transportes aéreos em Moçambique, desde a eclosão da pandemia, foram superiores à $80 \%$.

Em suma, todas as medidas tomadas por quase a totalidade dos países para tentar conter a propagação da pandemia da Covid-19, que insidiam essencialmente sobre as restrições à mobilidade humana, nomeadamente o isolamento/distanciamento social, o uso da máscara, a lavagem das mãos, entre outras, tiveram e continuam tendo grandes impactos negativos sobre o transporte, em especial o aéreo, e por conseguinte sobre o turismo, onde se destacam o encerramento de diversas infraestruturas turísticas, o desemprego massivo e as suas consequências socioesoaciais directas e indirectas, relacionadas à redução do consumo do espaço, sobretudo, dos lugares turísticos, alimentados pela mobilidade ora restringida e/ ou em alguns casos proibida.

\section{CONSIDERAÇÕES FINAIS}

A pandemia Covid-19 tem estado a reduzir os esforços de desenvolvimento de muitas nações, principalmente por inibir o funcionamento do terceiro sector, onde se enquadra o turismo. Com as limitações impostas pelos governos, as deslocações dentro e para fora dos países, igualmente, foram afectadas levando ao encerramento de fronteiras, facto que, igualmente, determinou o encerramento de aeroportos e outros tipos de terminais em destinos dependentes de fluxos turísticos para viabilizar o funcionamento do sector de transportes.

Paralelemente, por existirem dificuldades de mobilidade, elemento central na viabilização do turismo, outras áreas/sectores transversais foram afectadas, pois, com a redução de mobilidade, os custos operacionais 
deixaram de ser viáveis. O sector de transportes, principalmente o aéreo, que é um dos principais protagonistas na dinamização do turismo internacional e regional, observa um recrudescimento no crescimento afectando, igualmente, outros sectores que o dinamizam, exemplifica-se o sector de combustíveis para aeronaves, os serviços existentes em aeroportos como correios, restaurantes, lojas de souvenires, agências de aluguer de viaturas, entre outros.

Moçambique, país que observa índices baixos de desenvolvimento, igualmente, foi e está a ser afectado pela pandemia Covid-19. Os sectores de transportes e turismo, igualmente, conforme demonstrado neste trabalho a partir dos dados estatísticos disponibilizados pela empresa Aeroportos de Moçambique e outras fontes nacionais, apresentaram, no período em análise, reduções de crescimento desde a eclosão da pandemia, visto que, voos foram cancelados e aeroportos encerrados por determinação legal, como forma de conter a propagação do vírus. Neste diapasão, o número de passageiros, igualmente, reduziu consideravelmente.

A redução no número de chegadas de voos e passageiros/turistas, nacionais e estrangeiros, originou consequências negativas no sector do Turismo, pois, os habituais ou novos visitantes, foram obrigados a cancelar ou remanejar viagens, facto que ocasiona (ou) o encerramento de estabelecimentos turísticos em virtude da ausência de clientes. Este encerramento, conforme dados divulgados pelo MICULTUR e FEMOTUR, levou ao despedimento de milhares de trabalhadores que tinham a sua fonte de sustentabilidade no trabalho desenvolvido neste sector. Igualmente, o Governo, observou, no período em referência, redução na captação de receitas que contribuem para o financiamento das despesas públicas, principalmente socias.

Diante deste cenário calamitoso, onde politicas públicas coordenadas com o sector privado, são exíguas e pouco abrangentes, há necessidade de se repensar o sector e a gestão de crises, visto que, a curto, médio e longo prazo, outras pandemias ou fenómenos atmosféricos podem eclodir, impactando, igualmente, negativamente nestes dois sectores que se complementam.

A gestão de crise deve pensar, igualmente, em iniciativas e politicas públicas locais, uma vez que, decisões governamentais de nível central colocam todo um sector em desequilíbrio quando iniciativas locais podem ser uma forma de minimizar o impacto das restrições. Exemplifica-se as restrições de utilização de praias quando em locais como Vilanculo e Inhambane, há possibilidade de desenvolver uma actividade mais controlada, em praias isoladas e de difícil acesso, observando a capacidade de carga e tempo mínimo de permanência que permita que o turista, principalmente os de alta renda, possam continuar a viajar minimizando e garantindo o funcionamento dos estabelecimentos turísticos e infraestruturas aeroportuárias nacionais. Um encerramento total do sector gera uma catástrofe socioeconómica considerando que parte dos funcionários não receberam (em) assistência social pela perda de emprego ocasionado pela pandemia e que muitos são despedidos sem os direitos observados no acto de rescisão contratual. 
Há, de igual modo, primeiro, a necessidade de se repensar nas estratégias de desenvolvimento dos sectores de turismo e transporte em Moçambique, visto que, as actuais foram concebidas em um período em que não se cogitava tamanha proporção de uma pandemia como a Covid-19. Delinear estratégias robustas e eficientes para o pós-Covid-19 é uma premissa que deve merecer atenção dos intervenientes do processo de desenvolvimento do turismo e transportes em Moçambique.

Por fim, diante da situação calamitosa que se verifica nestes sectores desde o ano de 2020, fica evidente que os esforços para redução da pobreza e subdesenvolvimento, conforme descrito pelo Governo de Moçambique (2014) na Estratégia Nacional de Desenvolvimento 2014-2035, estão comprometidos, facto que requer muito envolvimento de todos intervenientes para se colmatar o que se observa no momento.

Vale reforçar que pesquisas adicionais, mais específicas sobre impactos da Covid-19, abarcando a totalidade dos sectores que estabelecem uma relação muito activa com o sector do Turismo são importantes recomendáveis.

\section{AGRADECIMENTOS}

O grupo de trabalho agradece ao MSc. Abrantes Mussafo, docente e investigador da Universidade Púnguè, Extensão de Tete, pelo apoio concedido na sistematização dos dados.

\section{REFERÊNCIAS}

AEROPORTOS DE MOÇAMBIQUE E.P. Evolução do Tráfego Anual de 2019 e 2020. Maputo: ADM, 2021

CARLOS, Ana. Turismo e produção do não lugar. IN: YÁZIGI, Eduardo; CARLOS, Ana; CRUZ, Rita (Org.). Turismo: Espaço, Paisagem e Cultura. São Paulo: Hucitec. 1996

CRUZ, Rita. Geografias do Turismo: De lugares aos pseudo-lugares. São Paulo: Roca. 2007.

CRUZ, Rita. Introdução à Geografia do Turismo. São Paulo: Roca, 2003.

CTA. Impacto do covid-19 no sector empresarial moçambicano e propostas de medidas para a sua mitigação. Maputo, Março, 2020. Disponível em: https://cta.org.mz/wp-content/uploads/2020/05/Estudo1-Impacto-da-COVID-19-em-Mo\%C3\%A7ambiqueVERS-AO-FINALLL-003.pdf acesso em 7/5/2020.

CTA \& FEMOTUR. Estímulos financeiros e eventuais prorrogações das medicas fiscais e financeiras introduzidas pelo Governo. Maputo: 2020.

CUNHA, JOSÉ. Turismo e Hotelaria em Moçambique: impactos da pandemia COVID-19. [Entrevista cedida a Helsio Azevedo]. ESHTI, Inhambane, 2021.

FRATUCCI, Aguinaldo; MORAES, Claudia; e ALLIS, Thiago: Espaços e territórios do turismo: eflexões e indagações. In: XII Seminário da Associação Nacional de Pesquisa e Pós-Graduação em Turismo. 2015. Disponível em: http://www.anptur.org.br/anptur/anais/v.11/DFP1 pdf/46.pdf. Acesso: 26/10/16.

GUAMBE, José. Efeitos da Pandemia de Covid19 sobre o turismo na África subsaariana e em Moçambique. AbeÁfrica-Revista da Associação Brasileira de Estudos Africanos, v.3, n.3, out. 2019. 
GUAMBE, José. Turismo na Zona Costeira de Inhambane: Conflitos na Produção do Espaço. Tese de Doutorado em Geografia, Universidade Pedagógica, Maputo, 2018.

JORNAL NOTICIAS. Aviação civil regista perdas superiores a 80 por cento. Maputo, ed. 31159, p. 1, 3 dez. 2020.

INSTITUTO NACIONAL DE ESTATÍSTICAS. Estatísticas do Turismo, 2016 - 2018. Maputo: INE, 2018.

KNAFOU, Remy. Turismo e território: Por uma abordagem científica do turismo. IN: RODRIGUES, Adyr (Org.): Turismo e Geografia Reflexões teóricas e enfoques regionais 2. ed. São Paulo: Hucitec. 1999, p 62-74.

MICULTUR. Impacto da Covid-19 no sector da cultura e turismo. Disponível em:

http://www.micultur.gov.mz/index.php/turismo/593-impacto-da-covid-19-no-sector-da-cultu-ra-e-turismo. Acesso em: 2/11/2020.

MISAU. Boletim diário Covid-19: №357. Disponível em: https://www.misau.gov.mz/index.php/covid-19-boletins-

diarios?download=880: boletim-diario-covid-19-n-357. Acesso: 8/03/2021.

MOÇAMBIQUE. Plano Estratégico para o Desenvolvimento do Turismo em Moçambique. Moçambique 2004-2013. Maputo: MITUR, 2004.

MOÇAMBIQUE. Estratégia Nacional de Desenvolvimento (2015-2035). Maputo, Julho de 2014. Disponivel:

https://www.mef.gov.mz/index.php/documentos/instrumentos-de-gestao/-2/397--3/file?force download=1. Acesso em 10/3/2021.

MOÇAMBIQUE. Conselho de Ministros. Decreto n. 12/2020 de 2 de Abril. Boletim da República. Imprensa Nacional: I SÉRIE, Maputo, 2020a, n. 64, p. 333-337, 2 abr. 2020a.

MOCAMBIQUE. Conselho de Ministros. Decreto n. 79/2020 de 4 de Setembro. Boletim da República. Imprensa Nacional: I SÉRIE, Maputo, 2020b. n. 171, p. 1-5, 4 Set. 2020b.

MONIÉ, Frédéric, A África subsaariana diante da pandemia de Coronavírus/COVID-19: difusão espacial, impactos e desafios. Espaço e Economia. Número 18, ANO IX, 2020 (1-26).

O'KEEFE, Brian. Mapping a contagion: How the coronavirus may spread around the world, 2020. Disponível em: https://fortune.com/longform/how-coronavirus-spread-map/. Acesso em: 03/06/2020.

RODRIGUES, Adyr. Turismo e Espaço: Rumo a um conhecimento transdisciplinar. São Paulo: Editora Hucitec, 1997.

SANTOS, Milton. Por uma outra globalização: do pensamento único à consciência universal. 2. ed. Rio de Janeiro: Record. 2000.

WHO. Coronavírus (COVID-19) Dashboard. Disponível em: https://www.who.int/emergencies/diseases/novel-coronavirus2019/situation-reports/. Acesso em 1/3/2021.

WORLDOMETER. Covid-19 Coronavirus Pandemic. Disponível em:

https://www.worldometers.info/coronavirus/?utm campaign=homeAdvegas1?. Acesso em: 14/03/2021. 